\title{
Eradication of $P$. aeruginosa biofilm in endotracheal tubes based on lock therapy: results from an in vitro study
}

\author{
María Jesús Pérez-Granda 1,2,3, María Consuelo Latorre" ${ }^{4}$, Beatriz Alonso ${ }^{2,5}$, Javier Hortal ${ }^{1,3}$, Rafael Samaniego ${ }^{2,6}$, \\ Emilio Bouza ${ }^{2,3,5,7}$ and María Guembe $2,5,8^{*}$ (1)
}

\begin{abstract}
Background: Despite the several strategies available for the management of biofilm-associated ventilator-associated pneumonia, data regarding the efficacy of applying antibiotics to the subglottic space (SS) are scarce. We created an in vitro model to assess the efficacy of antibiotic lock therapy (ALT) applied in the SS for eradication of Pseudomonas aeruginosa biofilm in endotracheal tubes (ETTS).

Methods: We applied $2 \mathrm{~h}$ of ALT to a P. aeruginosa biofilm in ETTs using a single dose (SD) and a 5-day therapy model (5D). We used sterile saline lock therapy (SLT) as the positive control. We compared colony count and the percentage of live cells between both models.

Results: The median (IQR) cfu counts/ml and percentage of live cells in the SD-ALT and SD-SLT groups were, respectively, $3.12 \times 10^{5}\left(9.7 \times 10^{4}-0\right)$ vs. $8.16 \times 10^{7}\left(7.0 \times 10^{7}-0\right)(p=0.05)$ and $53.2 \%(50.9 \%-57.2 \%)$ vs. $91.5 \%(87.3 \%-93.9 \%)(p<0.001)$.

The median (IQR) cfu counts/ml and percentage of live cells in the 5D-ALT and 5D-SLT groups were, respectively, $0(0-0)$ vs. $3.2 \times 10^{7}\left(2.32 \times 10^{7}-0\right)(p=0.03)$ and $40.6 \%(36.6 \%-60.0 \%)$ vs. $90.3 \%(84.8 \%-93.9 \%)(p<0.001)$.

Conclusion: We demonstrated a statistically significant decrease in the viability of $P$. aeruginosa biofilm after application of 5D-ALT in the SS. Future clinical studies to assess ALT in patients under mechanical ventilation are needed.

Keywords: Pseudomonas aeruginosa biofilm, Ventilator-associated pneumonia, Selective decontamination solution, Lock therapy, Confocal laser scanning microscopy
\end{abstract}

\section{Background}

Ventilator-associated pneumonia (VAP) is one of the most common nosocomial infections, with significant morbidity and mortality. Between $9 \%$ and $27 \%$ of intubated patients develop VAP, although the incidence can increase to $46 \%$ in patients who require mechanical ventilation for more than $48 \mathrm{~h}$ after major heart surgery (MHS) $[1,2]$.

Bacterial biofilm is thought to be responsible for the development of respiratory infections in more than $80 \%$ of cases, with approximately $10^{6}$ bacterial cells $/ \mathrm{cm}$ recovered from the endotracheal tube (ETT) [3]. In

\footnotetext{
* Correspondence: mariaguembe@hotmail.com

${ }^{2}$ Instituto de Investigación Sanitaria Gregorio Marañón, Madrid, Spain

${ }^{5}$ Department of Clinical Microbiology and Infectious Diseases, Hospital

General Universitario Gregorio Marañón, Madrid, Spain

Full list of author information is available at the end of the article
}

recent years, the association between VAP and biofilm has been well described, since pneumonia is associated more with the presence of biofilm than with duration of intubation $[4,5]$.

The various strategies for the prevention and treatment of VAP-associated biofilm include selective digestive decontamination (SDD), subglottic aspiration, antimicrobial drug-coated tubes, and devices that help to remove mucus, all of which can reduce biofilm formation in intubated patients [6-12]. Recent in vitro studies based on new designs of ETT have also described promising results regarding prevention of biofilm adhesion [13-16].

Despite the combination of compounds in the SDD solution would cover most microorganisms causing VAP and it even has not been associated to an increase of antibiotic resistance [17-20], it appears that SDD alone 
is not enough to reduce biofilm, as it only reaches the internal surface of the ETT [21, 22]. Therefore, an additional therapy with SDD solution directly applied at the external surface of the subglottic space can be a promising approach. Antibiotic lock therapy (ALT) is used for the prevention and treatment of catheterrelated bacteremia [23-26], but data on the use of an SDD solution as ALT in the prevention and treatment of VAP are scarce [27].

Therefore, our objective was to apply an in vitro bench top model to assess the efficacy of SDD solution applied in the subglottic space for eradication of Pseudomonas aeruginosa biofilm in ETTs.

\section{Methods}

Our prospective in vitro study was carried out in the laboratory of the Clinical Microbiology and Infectious Diseases Department, Hospital Gregorio Marañón, Madrid, Spain.

\section{Laboratory procedure}

We used a bench top in vitro model simulating adult tracheal intubation based on a cuffed ETT (TaperGuard Oral Tracheal Tube Evac Murphy Eye, Mallinckrodt ${ }^{\mathrm{m}}$ ) (Fig. 1a) [7]. The ETT was colonized with $3 \mathrm{ml}$ of a solution of $10^{8} \mathrm{cfu} / \mathrm{ml}$ of Pseudomonas aeruginosa ATCC 15442 in brain-heart infusion (BHI) and incubated at $37^{\circ} \mathrm{C}$ for $72 \mathrm{~h}$. BHI was discarded and replaced on each day of incubation. The model was run 4 times in order to test the following therapies: single dose of ALT (SD-ALT), 5 days of ALT (5D-ALT), single dose of sterile saline (SD-SLT), and 5-day SLT (5D-SLT). Sterile saline was used as a positive control (untreated). Each experiment was tested in triplicate (Fig. 1b).

Lock therapy consisted of a 2-h application of $3 \mathrm{ml}$ of either SDD solution (nystatin $2.6 \mathrm{mIU}$, tobramycin $15.6 \mathrm{mg} / \mathrm{ml}$, and colimycin $13 \mathrm{mg} / \mathrm{ml}$ ) or sterile saline in the subglottic space. In the case of 5D-ALT and 5D-SLT, we used BHI between lock therapy periods. We also assessed whether SDD solution or sterile saline leakage occurred during lock therapy.

Once lock therapy had finished, the solution was removed, and the ETTs were washed with sterile saline. The subglottic area of the ETT was then cut into 3 segments, each measuring $0.5 \mathrm{~cm}$ (Fig. 1b). One segment was sonicated in order to analyze the colony counts $(\mathrm{cfu} / \mathrm{ml})$ by culture and the percentage of live cells in the sonicate by image. The remaining 2 segments were processed to visualize biofilm biomass and sessile cell structure using microscopy.

\section{Analysis of colony counts and live cells in the sonicate}

Sonication was performed in $2 \mathrm{ml}$ of buffer solution for $1 \mathrm{~min}$ at $50 \mathrm{~Hz}$. For culture, the solution was serially diluted and cultured on blood agar plates, which were incubated for $24 \mathrm{~h}$ at $37^{\circ} \mathrm{C}$. Colony counts were expressed on a logarithmic scale as the number of $\mathrm{cfu} / \mathrm{ml}$.

For the analysis of the live/dead cells, the remaining sonicate was centrifuged (after culture), and the pellet was resuspended in $50 \mu \mathrm{l}$ of sterile saline and stained using the Live/Dead ${ }^{\oplus}$ BacLight kit $^{\mathrm{Tm}}$ (BacLight kit ${ }^{\mathrm{Tm}}$; Invitrogen, Barcelona, Spain) for 15 min protected from the light. Staining was performed using $0.5 \mu \mathrm{l}$ of $\mathrm{SYTO}^{\circ} 9$ (stock $3.34 \mathrm{mM}$ DMSO) and $0.5 \mu \mathrm{l}$ propidium iodide

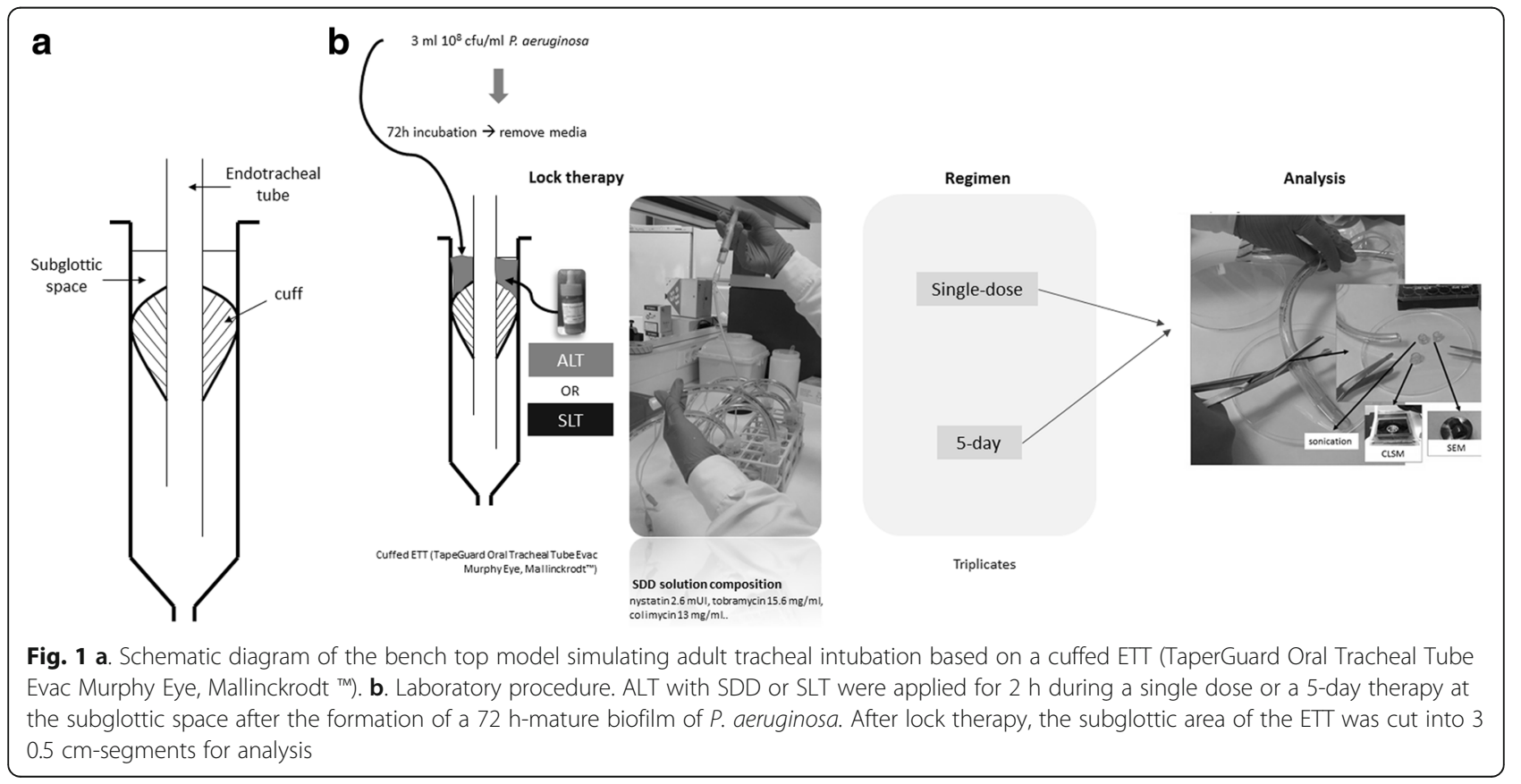


(stock $20 \mathrm{mM}$ DMSO) in $20 \mu \mathrm{l}$ of sample mounted on coverslips and imaged using confocal laser scanning microscopy (CLSM) in an inverted confocal fluorescence microscope (SPE, Leica Microsystems) equipped with ACS APO 10×/0.30 and ACS APO 63X/1.30 objectives. Samples were imaged using an ACS APO 63X/1.30 objective. During imaging, SYTO 9 emits green fluorescence and is used to identify living microorganisms with an intact membrane, whereas propidium iodide emits red fluorescence and stains dead bacteria with a damaged membrane. We analyzed 3 CLSM images of each sample. FIJI software (National Institute of Health, US) was used for image quantification. The percentage of live bacteria was calculated as the ratio between the number of live cells and the total number of cells $\times 100$.

\section{Visualization of biofilm biomass}

For visualization of the biofilm biomass in the ETT, we inactivated the ETT segments by freezing at $-80{ }^{\circ} \mathrm{C}$ for $72 \mathrm{~h}$. Then, after thawing for $30 \mathrm{~min}$, the segments were stained with the Live/Dead ${ }^{\circ}$ BacLight kit $^{\text {mix }}$ for $15 \mathrm{~min}$ protected from the light. Staining was performed using $1.5 \mu \mathrm{l}$ of $\mathrm{SYTO}^{\circ} 9$ (stock $3.34 \mathrm{mM}$ DMSO) and $1.5 \mu \mathrm{l}$ propidium iodide (stock $20 \mathrm{mM}$ DMSO) in $1 \mathrm{ml}$ phosphate-buffered saline. The samples were mounted on coverslips and imaged using CLSM at ACS APO 10X/0.30 objective $[28,29]$. We displayed 6 CLSM images for each sample. Images were edited using FIJI software (National Institute of Health, US).

\section{Visualization of sessile cell structure}

Biofilm structure was imaged using a $0.5-\mathrm{cm}$ half section of the ETT segment fixed in $2.5 \%$ glutaraldehyde and then in osmium tetroxide (1\%) and potassium ferricyanide $(0.8 \%)$. The samples were then dehydrated in graded alcohol and sputter-coated with gold atoms (Taab Laboratories Equipment Ltd., Berks, UK). Samples were imaged via a scanning electron microscope (SEM, T300, Jeol Ltd., Tokyo, Japan). We displayed 6 SEM images for each sample.

\section{Statistical analysis}

Qualitative variables appear with their frequency distribution. Quantitative variables are expressed as the median and interquartile range (IQR). Non-normally distributed continuous variables were compared using the Kruskal-Wallis and Mann-Whitney tests. The chisquare or Fisher exact test was used to compare categorical variables.

All statistical tests were 2-tailed. Statistical significance was set at $p<0.05$ for all the tests. The statistical analysis was performed with SPSS 21.0.

\section{Results and discussion}

\section{Single-dose lock therapy}

In the SD lock therapy model, culture of the sonicate of the ETT segments yielded a median (IQR) of $2.15 \times 10^{5}$ $\left(9.7 \times 10^{4}-0.0\right) \mathrm{cfu} / \mathrm{ml}$ in the SD-ALT group and $8.16 \times$ $10^{7}\left(7.0 \times 10^{7}-0.0\right) \mathrm{cfu} / \mathrm{ml}$ in the SD-SLT group $(p=0.05)$. The median (IQR) percentage of live cells detected by CLSM was $53.2 \%$ (50.9\%-57.2\%) in the SD-ALT group and $91.5 \%(87.3 \%-93.9 \%)$ in the SD-SLT group $(p<$ 0.001) (Fig. 2a, b).

The samples of ETT segments observed under CLSM showed a similar biomass thickness in $P$. aeruginosa biofilm for both SD-ALT and SD-SLT, as also shown by SEM. This finding correlated with the median (IQR) number of total cells: SD-ALT, 915.0 (279.0-1074.5) vs. SD-SLT, 246.0 (168.5-1130.5) ( $p=0.35$ ) (Fig. 2c). However, the $P$. aeruginosa cells in the SD-ALT group were deformed compared with the cells in the control group (Fig. 2d).

\section{5-day lock therapy}

Five-day lock therapy yielded a median (IQR) $\mathrm{cfu} / \mathrm{ml}$ from the sonicate of the ETT segments of $0.0(0.0-0.0)$ in the 5D-ALT group and $3.2 \times 10^{7}\left(2.32 \times 10^{7}-0.0\right)$ in the $5 \mathrm{D}-\mathrm{SLT}$ group $(p=0.03)$. The median (IQR) percentage of live cells in each group was $40.6 \%(36.6 \%-60.0 \%)$ for 5D-ALT and $90.3 \%(84.8 \%-93.9 \%)$ for 5D-SLT $(p<0.001)$ (Fig. 2a, b).

We also found statistically significant differences in the median (IQR) number of total cells: SD-ALT, 32.0 (28.0-35.5) vs. SD-SLT, $50.0(36.5-57.5)(p=0.01)$. This finding can be observed in the CLSM images of the ETT segments, in which the thickness of the biomass was lower for 5D-ALT (Fig. 2c).

In the SEM images of Fig. $2 \mathrm{~d}$, the bacilli of $P$. aeruginosa were almost eradicated, and the sample was composed mainly of crystals derived from the used fluids.

\section{Comparison between single-dose and 5-day lock therapy} In order to assess whether 5D-ALT was better than SDALT, we compared only the median between the percentage of live cells and the number of $\mathrm{cfu} / \mathrm{ml}$, as SD and $5 \mathrm{D}$ therapies were not comparable according to the total number of cells in both the ALT group and the SLT group. We found that $5 \mathrm{D}$-ALT was significantly better than SD-ALT in terms of the median (IQR) cfu/ml recovered in the sonicate: $0.0(0.0-0.0)$ vs. $2.15 \times 10^{5}(9.7 \times$ $\left.10^{4}-0.0\right)(p=0.04)$. Although there were no statistically significant differences in the median (IQR) percentage of live cells, 5D-ALT was slightly better than SD-ALT: $40.6 \%(36.6 \%-60.0 \%)$ vs. $53.2 \%(50.9 \%-57.2 \%)(p=0.12)$.

When we analyzed whether leakage of lock solutions occurred through the ETT, we did not recover any other solution in either the SD or the 5D lock therapies. 

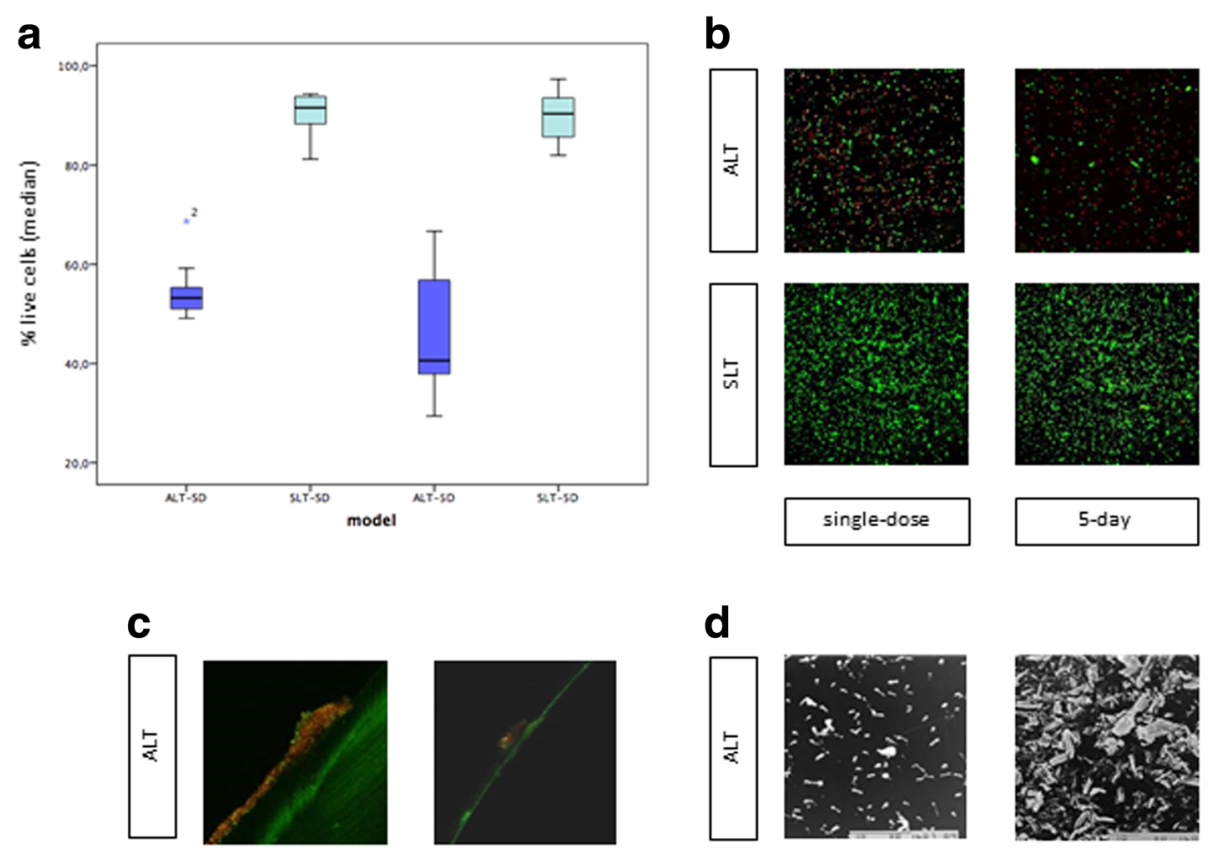

\section{d}
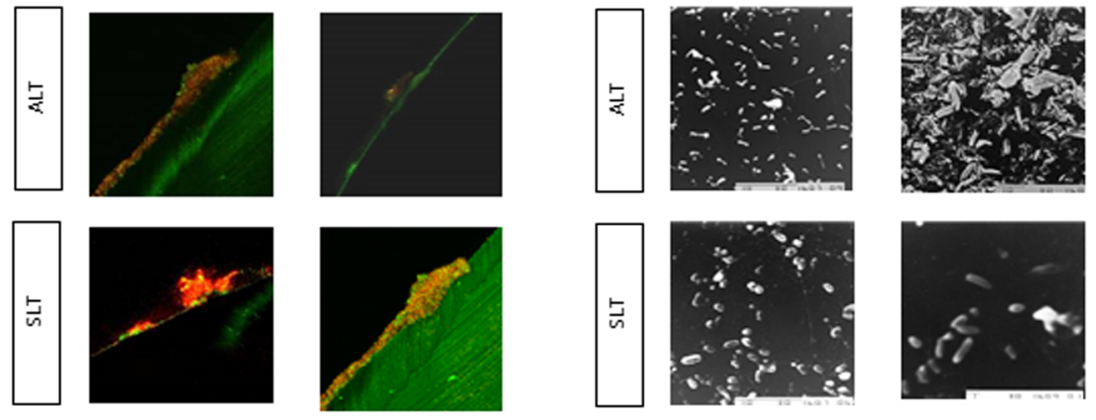

single-dose

5-day

single-dose

5-day

Fig. 2 a. Comparison of percentage of live cells between the lock therapy models. $P$ values were calculated by comparing the median (IQR) values using the Kruskal-Wallis test. $\mathbf{b}$. Confocal laser scanning micrograph of treated and non-treated biofilms of $P$. aeruginosa recovered from the sonicate of the endotracheal tube segments. Samples of the sonicate were stained using the Live/dead ${ }^{\circledR}$ BacLight kit ${ }^{\text {TM }}$ (magnification $\times 1500$ ). Bacteria recovered from 3 different ETTs were quantified (over 1000 cells per condition of single dose lock therapy and 5-day lock therapy). A single representative picture depicting the highest cell counts is reported for each model. c. Confocal laser scanning micrograph of the external surface of endotracheal tubes in the lock therapy and control groups. Samples were stained using the Live/dead ${ }^{\oplus}$ BacLight kit ${ }^{\text {TM }}$ (magnification $\times 250$ ). The white arrow indicated the endotracheal tube wall. A single representative picture depicting the greatest biofilm accumulation is reported for each model. $\mathbf{d}$. Scanning electron micrographs of the external surface of the endotracheal tubes in the lock therapy and control groups. Samples were fixed in glutaraldehyde, dehydrated in graded alcohol, and sputter-coated with gold atoms (magnification $\times 1500$ ). The white arrow indicated the distortion of sessile cells. A single representative picture depicting the greatest cell deformation is reported for each model. ALT, antibiotic lock therapy; SLT, saline lock therapy; SD, single dose; 5D, 5-day

Our in vitro data demonstrated that 5D-ALT using SDD solution applied on mature $P$. aeruginosa biofilm (72 h) in ETTs significantly reduced cell viability.

VAP is considered a major nosocomial infection, with a frequency ranging from $9 \%$ to $46 \%[2,30,31]$. The highest frequencies are described among patients in MHS intensive care units (MHS-ICUs), as demonstrated in previous studies, where the risk of VAP increased among patients undergoing mechanical ventilation for more than $16.6 \mathrm{~h}$ after MHS [2, 32].

Biofilm formation on the ETT surface plays a key role in the pathogenesis of VAP, as it prevents the action of antibiotics and host defense cells [33]. Persistence of biofilm in the ETT of microorganisms potentially causing VAP is a common phenomenon, and, despite the use of systemic and inhaled antibiotics, patients have a worse clinical response [34].
Several preventive measures, such as subglottic aspiration and SDD, have proven effective in the reduction of VAP rates among patients under mechanical ventilation [35]. In addition, it was recently demonstrated that the use of SDD in intubated patients admitted to MHS-ICUs significantly reduced the frequency of VAP episodes [11]. However, data on the possible role of SDD solution as lock therapy in the subglottic space are scarce. A clinical study by Pneumatikos et al. demonstrated that continuous infusion of an antibiotic solution in the subglottic space significantly reduced VAP rates [27]. In our study, we used sonication and CLSM to demonstrate that a 2-h application of the SDD solution in ETT contaminated with a mature $P$. aeruginosa biofilm was associated with a considerable reduction in the number of viable cells (both $\mathrm{cfu} / \mathrm{ml}$ and percentage of live cells). As for duration of 
lock therapy, even though the median percentage of live cells in the sonicate of the ETT segments treated with SDALT was significantly lower than in the control group (53.2\% vs. $91.5 \%, p<0.001)$, 5D-ALT not only significantly reduced the median percentage of live cells by $>50 \%$ ( $40.6 \%$ vs. $90.3 \%, p<0.001$ ), but it also reduced the median number of $\mathrm{cfu} / \mathrm{ml}\left(0.0\right.$ vs. $\left.3.2 \times 10^{7}, p=0.03\right)$. Our findings were also corroborated by direct observation of the biofilm in the ETT segments using CLSM and SEM, as 5D-ALT had a thinner biomass and the bacillus was deformed. This major cell damage observed by SEM was caused by tobramycin and colimycin, since both drugs produced leakage of cellular components, with the result that the cells were deformed [36].

We believe that the difference in the total number of cells observed in both periods of lock therapy is due to marked dislodgement of dead bacteria from the biofilm on the ETT surface in the 5D model [37]. Moreover, it was important to notice the difference between the $\mathrm{cfu} / \mathrm{ml}$ obtained from cultures and the percentage of live cells of the sonicate. This can be a limitation of the study due to the possible presence of viable but no-culturable cells (VBNC) or due to a lack of use of a neutralizing fluid during sample extraction, but this last procedure could have affected also the biofilm structure by dislodgement [38].

Finally, even though our in vitro model was based on a static pre-established $P$. aeruginosa biofilm, our data support using the ALT not only as a therapeutic measure once the biofilm is established, but also as a preventive measure in patients who are expected to be under mechanical ventilation for more than $48 \mathrm{~h}$ (from the beginning of intubation until extubation or until discharge from the ICU). Moreover, the combination of compounds in the SDD solution would cover most microorganisms causing VAP. However, despite in ICUs with low levels of antibiotic resistance there is no evidence that universal use of SDD increases antibiotic resistance, in ICUs with high endemic levels of antibiotic resistance, SDD may increase the selective pressure for antibiotic-resistant microorganisms [17-20]. Routine prophylactic use of antibiotics should be carefully introduced in hospital settings where there are high levels of antibiotic resistance [1]. Besides, the in vitro efficacy of this therapy on the biofilm of other microorganisms causing VAP (eg, Escherichia coli and Staphylococcus aureus) should be tested.

\section{Conclusion}

This is the first in vitro study demonstrating by culture and microscopy that $P$. aeruginosa biofilm in ETT can be significantly eradicated after applying ALT with SDD solution in the subglottic space. Future studies are needed to further evaluate the efficacy of this approach when combined with SDD as a prophylactic measure for VAP in patients under mechanical ventilation.

\section{Abbreviations}

5D: 5-day; ALT: Antibiotic lock therapy; CLSM: Confocal laser scanning microscopy; ETT: Endotracheal tube; SD: Single dose; SDD: Selective digestive decontamination; SEM: Scanning electron microscopy; SLT: Saline lock therapy

\section{Acknowledgements}

We thank Thomas O'Boyle for his help in the preparation of the manuscript and Julio García for his help in the preparation and analysis of the images of the scanning electron microscopy.

\section{Funding}

M. Guembe is supported by the Miguel Servet Program (ISCIII-MICINN, CP13/ 00268) from the Health Research Fund (FIS) of the Carlos III Health Institute (ISCIII), Madrid, Spain. Beatriz Alonso is supported by the Consejería de Educación, Juventud y Deporte de la Comunidad de Madrid and Fondo Social Europeo (PEJ15/BIO/Al-0406). The study was partially financed by the European Regional Development Fund (FEDER) "A way of making Europe" and by grants from the Instituto de Investigación Sanitaria Gregorio Marañón (II-PI-MGR-2016).

\section{Availability of data and materials}

The datasets used and/or analysed during the current study are available from the corresponding author on reasonable request.

\section{Authors' contributions}

MJP-G contributed in the conception and design of the study and had full access to all of the study data. She takes responsibility for the integrity of the data and the accuracy of the data analysis. MCL and BA made substantial contributions to acquisition, analysis, and interpretation of data. JH, and EB contributed substantially to the study design, data analysis and interpretation, and the writing of the manuscript. MG contributed to the conception and design of the study and data analysis and interpretation and was involved in drafting the manuscript and critically reviewing it for important intellectual content. All authors read and approved the final manuscript.

Ethics approval and consent to participate

The study was approved by Comité de Investigación Clínica del Hospital General Universitario Gregorio Marañón (approval number: MICRO.HGUGM.2015-075).

Consent for publication Not applicable.

\section{Competing interests}

The authors declare that they have no competing interests.

\section{Publisher's Note}

Springer Nature remains neutral with regard to jurisdictional claims in published maps and institutional affiliations.

\section{Author details}

${ }^{1}$ Cardiac Surgery Postoperative Care Unit, Hospital General Universitario Gregorio Marañón, Madrid, Spain. ${ }^{2}$ Instituto de Investigación Sanitaria Gregorio Marañón, Madrid, Spain. ${ }^{3}$ CIBER Enfermedades Respiratorias-CIBERES (CB06/06/0058), Madrid, Spain. ${ }^{4}$ Biology Department, School of Biology, Universidad Complutense de Madrid, Madrid, Spain. ${ }^{5}$ Department of Clinical Microbiology and Infectious Diseases, Hospital General Universitario Gregorio Marañón, Madrid, Spain. ${ }^{6}$ Confocal Laser Scanning Microscopy Unit, Hospital General Universitario Gregorio Marañón, Madrid, Spain. ${ }^{7}$ Medicine Department, School of Medicine, Universidad Complutense de Madrid, Madrid, Spain. ${ }^{8}$ Servicio de Microbiología Clínica y Enfermedades Infecciosas, Hospital General Universitario "Gregorio Marañón", C/. Dr. Esquerdo, 46, 28007 Madrid, Spain. 
Received: 8 June 2017 Accepted: 26 November 2017 Published online: 04 December 2017

\section{References}

1. American Thoracic Society; Infectious Diseases Society of America Guidelines for the management of adults with hospital-acquired, ventilatorassociated, and healthcare-associated pneumonia. Am J Respir Crit Care Med. 2005;171(4):388-416

2. Hortal J, Munoz P, Cuerpo G, Litvan H, Rosseel PM, Bouza E. Ventilator-associated pneumonia in patients undergoing major heart surgery: an incidence study in Europe. Crit Care. 2009;13(3):R80.

3. Inglis TJ, Millar MR, Jones JG, Robinson DA. Tracheal tube biofilm as a source of bacterial colonization of the lung. J Clin Microbiol. 1989;27(9): 2014-8.

4. Danin PE, Girou E, Legrand P, Louis B, Fodil R, Christov C, et al. Description and microbiology of endotracheal tube biofilm in mechanically ventilated subjects. Respir Care. 2015;60(1):21-9.

5. Vandecandelaere I, Coenye T. Microbial composition and antibiotic resistance of biofilms recovered from endotracheal tubes of mechanically ventilated patients. Adv Exp Med Biol. 2015;830:137-55.

6. Bouza E, Perez MJ, Munoz P, Rincon C, Barrio JM, Hortal J. Continuous aspiration of subglottic secretions in the prevention of ventilator-associated pneumonia in the postoperative period of major heart surgery. Chest. 2008; 134(5):938-46.

7. Carter EL, Duguid A, Ercole A, Matta B, Burnstein RM, Veenith T. Strategies to prevent ventilation-associated pneumonia: the effect of cuff pressure monitoring techniques and tracheal tube type on aspiration of subglottic secretions: an in-vitro study. Eur J Anaesthesiol. 2014;31(3):166-71.

8. Liu W, Zuo Z, Ma R, Zhang X. Effect of mechanical cleaning of endotracheal tubes with sterile urethral catheters to reduce biofilm formation in ventilator patients. Pediatr Crit Care Med. 2013;14(7):e338-43.

9. Mietto C, Foley K, Salerno L, Oleksak J, Pinciroli R, Goverman J, et al. Removal of endotracheal tube obstruction with a secretion clearance device. Respir Care. 2013;59(9):e122-6

10. Perez Granda MJ, Barrio JM, Hortal J, Munoz P, Rincon C, Bouza E. Routine aspiration of subglottic secretions after major heart surgery: impact on the incidence of ventilator-associated pneumonia. J Hosp Infect. 2013;85(4):312-5

11. Pérez-Granda MJ. BJ, Hortal J., Burillo A. Impact of selective digestive decontamination without systemic antibiotics in a Major Heart Surgery ICU (MHS-ICU). LI National Congress of SEMICYUC. Oral pressentation. 19-22 june, Valencia, Spain. 2016

12. Pinciroli R, Mietto C, Piriyapatsom A, Chenelle CT, Thomas JG, Pirrone M, et al. Endotracheal tubes cleaned with a novel mechanism for secretion removal: a randomized controlled clinical study. Respir Care. 2016;

13. Mann EE, Magin CM, Mettetal MR, May RM, Henry MM, De Loid H, et al. Micropatterned Endotracheal Tubes Reduce Secretion-Related Lumen Occlusion. Ann Biomed Eng. 2016:44(12):3645-54.

14. Machado MC, Webster TJ. Decreased Pseudomonas Aeruginosa biofilm formation on nanomodified endotracheal tubes: a dynamic lung model. Int J Nanomedicine. 2016;11:3825-31.

15. Jiang $X$, Lv B, Shen Q, Wang X. Preparation of silicon-modified antimicrobial polyethylene endotracheal tubes. J Biomed Mater Res B Appl Biomater. 2015;

16. May RM, Hoffman MG, Sogo MJ, Parker AE, O'Toole GA, Brennan AB, et al. Micro-patterned surfaces reduce bacterial colonization and biofilm formation in vitro: potential for enhancing endotracheal tube designs. Clin Transl Med. 2014;3:8.

17. Krueger WA, Lenhart FP, Neeser G, Ruckdeschel G, Schreckhase H, Eissner $\mathrm{HJ}$, et al. Influence of combined intravenous and topical antibiotic prophylaxis on the incidence of infections, organ dysfunctions, and mortality in critically ill surgical patients: a prospective, stratified, randomized, double-blind, placebo-controlled clinical trial. Am J Respir Crit Care Med. 2002;166(8):1029-37.

18. de Jonge E, Schultz MJ, Spanjaard L, Bossuyt PM, Vroom MB, Dankert J, et al. Effects of selective decontamination of digestive tract on mortality and acquisition of resistant bacteria in intensive care: a randomised controlled trial. Lancet. 2003:362(9389):1011-6.

19. Daneman N, Sarwar S, Fowler RA, Cuthbertson BH. Effect of selective decontamination on antimicrobial resistance in intensive care units: a systematic review and meta-analysis. Lancet Infect Dis. 2013;13(4):328-41.
20. Plantinga NL, Bonten MJ. Selective decontamination and antibiotic resistance in ICUs. Crit Care. 2015:19:259.

21. Adair CG, Gorman SP, O'Neill FB, McClurg B, Goldsmith EC, Webb CH. Selective decontamination of the digestive tract (SDD) does not prevent the formation of microbial biofilms on endotracheal tubes. J Antimicrob Chemother. 1993;31(5):689-97.

22. Gorman S, Adair C, O'Neill F, Goldsmith C, Webb H. Influence of selective decontamination of the digestive tract on microbial biofilm formation on endotracheal tubes from artificially ventilated patients. Eur J Clin Microbiol Infect Dis. 1993;12(1):9-17.

23. Bleyer AJ. Use of antimicrobial catheter lock solutions to prevent catheter-related bacteremia. Clin J Am Soc Nephrol. 2007;2(5):1073-8.

24. del Pozo JL. Role of antibiotic lock therapy for the treatment of catheter-related bloodstream infections. Int J Artif Organs. 2009;32(9): 678-88.

25. Fernandez-Hidalgo N, Almirante B. Antibiotic-lock therapy: a clinical viewpoint. Expert Rev Anti-Infect Ther. 2013;12(1):117-29.

26. Liu Y, Zhang AQ, Cao L, Xia HT, Ma JJ. Taurolidine lock solutions for the prevention of catheter-related bloodstream infections: a systematic review and meta-analysis of randomized controlled trials. PLoS One. 2013;8(11): e79417.

27. Pneumatikos IA, Dragoumanis CK, Bouros DE. Ventilator-associated pneumonia or endotracheal tube-associated pneumonia? An approach to the pathogenesis and preventive strategies emphasizing the importance of endotracheal tube. Anesthesiology. 2009;110(3):673-80.

28. Fernandez-Barat L, Ferrer M, Sierra JM, Soy D, Guerrero L, Vila J, et al. Linezolid limits burden of methicillin-resistant Staphylococcus Aureus in biofilm of tracheal tubes. Crit Care Med. 2012;40(8):2385-9.

29. Fernandez-Barat L, Li Bassi G, Ferrer M, Bosch A, Calvo M, Vila J, et al. Direct analysis of bacterial viability in endotracheal tube biofilm from a pig model of methicillin-resistant Staphylococcus Aureus pneumonia following antimicrobial therapy. FEMS Immunol Med Microbiol. 2012;65(2):309-17.

30. Kollef MH, Chastre J, Fagon JY, Francois B, Niederman MS, Rello J, et al. Global prospective epidemiologic and surveillance study of ventilatorassociated pneumonia due to Pseudomonas Aeruginosa. Crit Care Med. 2014;42(10):2178-87

31. Lizan-Garcia M, Peyro R, Cortina M, Crespo MD, Tobias A. Nosocomial infection surveillance in a surgical intensive care unit in Spain, 1996-2000: a time-trend analysis. Infect Control Hosp Epidemiol. 2006;27(1):54-9.

32. Poelaert J, Haentjens P, Blot S. Association among duration of mechanical ventilation, cuff material of endotracheal tube, and postoperative nosocomial pneumonia in cardiac surgical patients: a prospective study. J Thorac Cardiovasc Surg. 2014;148(4):1622-7.

33. Gil-Perotin S, Ramirez P, Marti V, Sahuquillo JM, Gonzalez E, Calleja I, et al. Implications of endotracheal tube biofilm in ventilator-associated pneumonia response: a state of concept. Crit Care. 2012;16(3):R93.

34. Gordon Sahuquillo M, Geffner P, Aroca M, Villarreal Tello E, Ruiz Ramos J, Ruiz Orenga B, et al. Impact of persistent endotracheal tube biofilm on ventilator-associated pneumonia clinical and microbiological response. Intensive Care Med Exp. 2015:3(Suppl 1):A700.

35. Berra L, De Marchi L, Panigada M, Yu ZX, Baccarelli A, Kolobow T. Evaluation of continuous aspiration of subglottic secretion in an in vivo study. Crit Care Med. 2004:32(10):2071-8

36. Naghmouchi K, Baah J, Hober D, Jouy E, Rubrecht C, Sane F, et al. Synergistic effect between colistin and bacteriocins in controlling gram-negative pathogens and their potential to reduce antibiotic toxicity in mammalian epithelial cells. Antimicrob Agents Chemother. 2013;57(6):2719-25

37. Klare W, Das T, Ibugo A, Buckle E, Manefield M, Manos J. The glutathionedisrupted biofilm of clinical Pseudomonas Aeruginosa strains: enhanced antibiotic effect and a novel biofilm transcriptome. Antimicrob Agents Chemother. 2016;60(8):4539-51.

38. Li L, Mendis N, Trigui H, Oliver JD, Faucher SP. The importance of the viable but non-culturable state in human bacterial pathogens. Front Microbiol. 2014;5:258. 